\title{
Atividade antimicrobiana in vitro dos óleos essenciais de orégano, alho, cravo e limão sobre bactérias patogênicas isoladas de vôngole
}

\section{In vitro antimicrobial activity of essential oils from oregano, garlic, clove and lemon against pathogenic bacteria isolated from Anomalocardia brasiliana}

\author{
Juliana Cantalino Santos ${ }^{1 *}$; Celso Duarte Carvalho Filho²; Tânia Fraga Barros; \\ Alaíse Gil Guimarães ${ }^{2}$
}

\begin{abstract}
Resumo
Antimicrobianos de origem natural são alternativas eficazes e econômicas, pois são obtidos a partir das plantas aromáticas e especiarias ricas em óleos essenciais caracterizados por uma notável atividade antimicrobiana, e por esta razão, seus produtos derivados podem ser usados para retardar ou inibir a multiplicação microbiana. O objetivo deste estudo foi avaliar a atividade antibacteriana dos óleos essenciais de cravo, limão, orégano e alho sobre as cepas de Staphylococcus aureus e Escherichia coli isolados do vôngole (Anomalocardia brasiliana) e cepas padrão ATCC (American Type Culture Collection): Escherichia coli, Staphylococcus aureus e Salmonella cholerasuis, através da técnica de difusão de disco e em seguida a determinação da Concentração Inibitória Mínima (CIM). Neste estudo observou-se que o óleo essencial de alho apresentou atividade antibacteriana frente o $S$. aureus e a $S$. cholerasuis; já os óleos de cravo e orégano apresentaram atividade frente a todas as bactérias analisadas, no entanto o óleo de orégano apresentou maiores halos de inibição bacteriana, $26,7 \mathrm{~mm}$ e $29,3 \mathrm{~mm}$ para as cepas de $E$. coli e $S$. aureus, respectivamente. O óleo essencial de limão não demonstrou atividade antibacteriana. Desta forma os óleos essenciais de cravo e orégano demonstraram as melhores atividades antibacterianas e assim apresentam-se como óleos favoráveis para a aplicação em alimentos.
\end{abstract}

Palavras-chave: Óleo essencial, Anomalocardia brasiliana, atividade antimicrobiana

\begin{abstract}
Natural preservative substances are an efficient and economic alternative, because the aromatical plants and rich spices in essential oils characterized by a notable are gotten from antimicrobial activity, and for this reason, its derived products can be used to delay or to inhibit the growth of microorganisms. The objective of this study was to evaluate the antibacterial activity of essential oils of clove, limon, oregano (Origanum vulgare ssp. Hirtum) and garlic several species of bacteria like Staphylococcus aureus and Escherichia coli isolated of vongole (Anomalocardia Brasiliana) and bacteria standard ATCC (American Type Culture Collection): Escherichia coli, Staphylococcus aureus and Salmonella cholerasuis, through diffusion test and after it was determinate the Minimum Inhibitory Concentration (MIC). In this study it was observed that the garlic essential oil presented antibacterial activity front the
\end{abstract}

\footnotetext{
${ }^{1}$ Discente, curso de Pós-graduação em Ciência de Alimentos da Faculdade de Farmácia da Universidade Federal da Bahia, UFBA. E-mail: jucantalino@hotmail.com

2 Prof. Adjunto, curso de Pós-graduação em Ciência de Alimentos da Faculdade de Farmácia, UFBA. E-mail: celsodc@ufba.br; alaise@ufba.br

3 Prof. Adjunto, curso de Pós-graduação em Microbiologia Clínica do Dept ${ }^{\circ}$ de Análises Clínicas e Toxicológicas da UFBA. E-mail: tfbarros@uol.com.br

*Autor para correspondência
} 
S. aureus and the S. cholerasuis.; already the oils of clove and oregano (Origanum vulgare ssp. Hirtum) had presented activity front to all the analyzed bacteria, however the oregano oil presented the bigger bacterial inhibition, $26.7 \mathrm{~mm}$ e $29,3 \mathrm{~mm}$ for $E$. coli e $S$. aureus respectively. The essential oil of lemon did not demonstrate antibacterial activity. In such a way the oregano and clove essential oils that they had presented antibacterial activity appeared to be the most preferable agent for future research.

Key words: Essential oil, Anomalocardia brasiliana, antibacterial activity

\section{Introdução}

As propriedades biológicas dos óleos essenciais extraídos de plantas aromáticas e medicinais têm sido exploradas há muitos anos e atualmente, o uso de compostos antimicrobianosnaturaistemse intensificado com o propósito de serem aplicados na conservação de alimentos (KRUGER, 2006; BUSSATA et al., 2007; BURT, 2004; DORMANS; DEANS, 1995).

Os condimentos são de origem vegetal, sendo freqüentemente utilizados para conferir sabor agradável aos alimentos, no entanto, ricos em óleos essenciais, são misturas naturais complexas de metabólitos secundários voláteis, podendo ser isolados de plantas por arraste a vapor. Os óleos essenciais são formados por mais de 100 componentes, responsáveis por seu odor e aroma (NASCIMENTO et al., 2007) e a sua utilização como antimicrobiano tem sido bastante pesquisada por se tratar de substituintes mais seguros para a conservação dos alimentos em relação aos aditivos químicos.

Além dos condimentos como agentes antimicrobianos, a utilização de sumos de frutas e hortaliças utilizados na dieta, apresenta-se como uma possibilidade para o desenvolvimento de uma terapêutica simples no combate a doenças infecciosas repercutindo na qualidade de vida de milhões de consumidores além do impulso técnico, cientifico e financeiro (ARAÚJO, 2007).

Segundo Souza (2006), uma das maiores dificuldades para o uso de antimicrobianos emalimentos são as barreiras de regularização do aditivo, embora em países como os Estados Unidos vários componentes de óleos essenciais são registrados para uso como flavorizantes em alimentos. No Brasil, substâncias utilizadas como aromatizantes naturais em alimentos são isentos de registro no Ministério da Saúde sendo permitida a sua utilização (BRASIL, 2005). Estes flavorizantes são considerados sem nenhum risco para a saúde dos consumidores, o que inclui o carvacrol, carvona, cinamaldeido, citral, eugenol, mentol, timol, p-cimeno, limoneno, entre outros (LAMBERT et al., 2001). Porém substâncias como o metil eugenol e estragol são considerados tóxicos e tem sua inclusão proibida nos alimentos (BURT, 2004).

Vários condimentos e especiarias são bastante conhecidos pelo seu poder bactericida. Dentre estes condimentos, destaca-se o alho, sendo sua atividade antimicrobiana descrita por vários autores sendo a alicina o componente de inibição (BURT, 2004; MENDONÇA, 2004; PEREIRA et al., 2008). Indu et al. (2006), relataram que o alho apresentou atividade antibacteriana excelente em todas as concentrações testadas $(100 \%, 75 \%, 50 \%$ e $25 \%)$ a diferentes cepas de Escherichia coli.

Em produto altamente perecível como carnes e pescados torna-se indispensável à ação de agentes antimicrobianos para preservar a sua qualidade e segurança por um período maior de tempo, além disso, do ponto de vista sensorial a combinação de aromas com alho é uma prática tempero comum na Europa e na América Latina e bem aceito pelos consumidores (AYALA-ZAVALA; GONZÁLEZ-AGUILAR; DELTORO-SÁNCHEZ, 2009).

Bernbom et al. (2009) avaliaram a atividade antimicrobiana do cloreto de sódio, acido lático e alho sobre micro-organismos patogênicos em produto de peixe fermentado e constaram que o extrato de alho, nas concentrações de 0 ate $10 \%$ não apresentava atividade inibitória sobre a bactéria Salmonella enterica serovar Enteritidis, no entanto o Vibrio spp. foi inibido por 1,0$1,5 \%$ deste extrato. 
Bodini et al. (2009) estudando a atividade do extrato de alho sobre o quorum-sensing (QS) dos micro-organismos Escherichia coli, Agrobacterium tumefaciens, Chromobacterium violaceum, Pseudomonas e Pseudomonas chlororaphise relataram o poder inibitório deste extrato no desenvolvimento desses micro-organismos. Os óleos essenciais como novo princípio antibacteriano, devido à sua atividade anti- quorum-sensing pode ser importante na redução de virulência e patogenicidade de bactérias resistentes aos medicamentos in vivo (KHAN et al., 2009).

Dentre outros óleos essenciais com propriedades antimicrobianas, destaca-se o cravo (Eugenia caryophyllata), que é conhecido por seu poder anestésico, analgésico local, anti-inflamatório e efeitos antibacterianos (HEMAISWARYA; DOBLE, 2009), e o óleo essencial de limão (Citrus limon L.) que possui como principais constituintes o limoneno, $\beta$ - pineno, $\gamma$-terpineno e citral (neral e geranial). O óleo essencial de limão tem constituintes como o limoneno e o citral, com atividade antibacteriana sobre as bactérias E.coli e S. aureus constatada (MISHARINA; SAMUSENKO, 2008; SCHUCK et al., 2001).

O presente trabalho teve como objetivo determinar a atividade antimicrobiana in vitro e determinar a concentração inibitória mínima (CIM) de quatro óleos essenciais (orégano, cravo, limão e alho) da mesma marca comercial sobre diferentes micro-organismos.

\section{Material e Métodos}

\section{Micro-organismos}

ForamtestadosStaphylococcusaureus eEscherichia coli isolados do vôngole (Anomalocardia brasiliana), obtidos do projeto "Avaliação microbiológica e apoio a melhoria na qualidade de mariscos processados e comercializados por "mariscadeiras", da Baía de Todos os Santos" desenvolvido no Laboratório de Microbiologia dos Alimentos da Faculdade de Farmácia da Universidade Federal da Bahia. Foram utilizadas também bactérias cepas padrão ATCC (American Type Culture Collection): Escherichia coli
(ATCC 25922), Staphylococcus aureus (ATCC 25923) e Salmonella cholerasuis (ATCC 10708) do banco de cepas do laboratório de Pesquisa em Microbiologia Clínica (LPMC) da Faculdade de Farmácia da Universidade Federal da Bahia. Todas as bactérias foram armazenadas sob congelamento em freezer à temperatura de $-20^{\circ} \mathrm{C}$ e 24 horas antes da realização do experimento, foram repicados em Ágar de Soja Tripticaseína (TSA) e incubados a $35^{\circ} \mathrm{C}$.

\section{Óleos essenciais}

O óleo essencial de cravo (Eugenia caryophyllata) possui $90 \%$ de eugenol. O óleo essencial de orégano (Origanum vulgare ssp. Hirtum) apresenta $80 \%$ de carvacrol, o óleo essencial da casca do limão siciliano (Citrus limonum medica) apresenta 60\% de d-limoneno e o óleo essencial de alho (Allium sativum) (LASZLO, 2010).

Foram testados óleos essenciais disponíveis no comércio da marca Laszlo Aromalândia (São Paulo- Brasil), como o óleo essencial de alho (Allium sativum), óleo essencial de cravo botões (Eugenia caryophyllata), óleo essencial de orégano (Origanum vulgare ssp. Hirtum) e óleo essencial da casca do limão siciliano (Citrus limonum medica).

A empresa Laszlo Aromalândia (Autorização para funcionamento/ANVISA $n^{0}$ 2.04.758-2) é uma empresa que comercializa óleos essenciais para diversas áreas, desde ao uso em alimentos, cosméticos, farmacêuticos, entre outros. Os óleos essenciais estudados são comercializados para a aplicação em alimentos e conforme a legislação específica, este tipo de produto para a utilização em alimentos são isentos de registro no Ministério da Saúde (BRASIL, 2005).

\section{Teste de susceptibilidade in vitro}

A atividade antibacteriana dos óleos essenciais foi testada através da técnica de difusão de disco de acordo com o protocolo M2-A8 do "National Committee for Clinical Laboratory Standard” (NCCLS, 2000), 
adaptado para produtos naturais.

De um crescimento bacteriano de 18 a 24 horas, foram inoculadas três a cinco Unidades Formadoras de Colônia (UFC) em $5 \mathrm{~mL}$ de solução salina a $0,85 \%$, com auxílio de alça bacteriológica, previamente flambada. A suspensão obtida teve a turvação ajustada por comparação visual à suspensão padrão 0,5 da escala de McFarland. Com o auxílio de swab estéril, a suspensão foi semeada na superfície de uma placa de ágar Müller-Hinton, em três direções até a obtenção de um esfregaço uniforme. Após a secagem do inóculo, foram aplicados discos de papel de filtro, com $6 \mathrm{~mm}$ de diâmetro, impregnados com $5 \mu \mathrm{L}$ de cada óleo essencial. As leituras foram realizadas, após 18 a 24 horas de incubação a $35-37 \mathrm{oC}$, por meio da medição dos halos de inibição de crescimento bacteriano em milímetros de diâmetro. Controles de qualidade foram realizados com as cepas padrão e disco de cloranfenicol $(30 \mu \mathrm{g}-\mathrm{CECON})$.

\section{Determinação da Concentração Inibitória Mínima}

A Concentração Inibitória Mínima (CIM) foi determinada através da técnica de difusão em poços, conforme metodologia adaptada de Kruger (2006).

A suspensão bacteriana foi procedida como descrita no item anterior para o padrão $0,5 \mathrm{McF}$ arland, correspondente a $10^{8}$ células $/ \mathrm{mL}$. Um $\mathrm{mL}$ da suspensão foi homogeneizada a $19 \mathrm{~mL}$ de ágar Muller Hinton fundido e resfriado a $45^{\circ} \mathrm{C}-50^{\circ} \mathrm{C}$ em seguida transferido para a placa de Petri contendo um fino filme de ágar bacteriológico a $1 \%$ e 5 ponteiras estéreis vertidas, para a obtenção dos poços. Após solidificação, as ponteiras foram retiradas e foram aplicados $50 \mu \mathrm{L}$ dos óleos essenciais, nas diluições $0,1 \%, 0,5 \%, 1 \%, 2,5 \%$, $5 \%, 10 \%, 20 \%, 30 \%, 40 \%$ e $50 \%$, em cada poço. A incubação foi feita a $35-37$ oC por 24 horas e após este período de incubação os diâmetros dos halos formados foram medidos (em milímetros).

\section{Análise estatística}

Os dados foram submetidos a análise de variância (ANOVA) e a diferença entre as amostras foi avaliada segundo o teste de Tukey a 5\% de significância.

\section{Resultados e Discussão}

Como podem ser observados na Tabela 1, os óleos essenciais de cravo e orégano apresentaram atividade frente a todas as bactérias analisadas. Já o óleo essencial de alho apresentou atividade antibacteriana frente o $S$. aureus e a S. choleraesuis. O óleo de orégano apresentou maiores halos de inibição bacteriana e o óleo essencial de limão não demonstrou atividade antibacteriana.

Tabela 1. Atividade antibacteriana de diferentes óleos essenciais.

\begin{tabular}{lcccc}
\hline Bactérias & \multicolumn{4}{c}{ Óleos essenciais } \\
\cline { 2 - 5 } Isolados do vôngole & Limão & Alho & Cravo & Orégano \\
\cline { 2 - 5 } S.aureus isolado 1 & NI & $40 \pm 0$ & $11 \pm 0$ & $26.7 \pm 0.33$ \\
S.aureus isolado 2 & NI & $40 \pm 0$ & $13,3 \pm 0,33$ & $28 \pm 1$ \\
E. coli isolado 1 & NI & NI & $10,3 \pm 0,33$ & $23.7 \pm 0.33$ \\
E. coli isolado 2 & NI & NI & $10,7 \pm 0.33$ & $20,3 \pm 2.33$ \\
Cepas padrão ATCC & NI & & & \\
Salmonella cholerasuis & NI & $39.7 \pm 0.33$ & $8.7 \pm 0.33$ & $14.3 \pm 0.33$ \\
S.aureus & NI & $40 \pm 0$ & $15,7 \pm 0.33$ & $29,3 \pm 0.33$ \\
E.coli & NI & NI & $11 \pm 0$ & $27,7 \pm 2.33$ \\
\hline NI (Não halos em milímetros)
\end{tabular}

NI (Não houve inibição). 
Através da analise estatística (ANOVA) dos resultados obtidos na Tabela 1 , conclui-se que existe diferença significativa entre a ação dos diferentes óleos essências, frente as mesma bactéria analisada.

$\mathrm{Na}$ Tabela 1 pode-se observar ainda que as cepas de $S$. aureus foram mais susceptíveis aos óleos de cravo, orégano e alho que as demais cepas. $\mathrm{O}$ mesmo resultado foi verificado pelos estudos de Dormans e Deans (2000), após utilizarem óleos essenciais de orégano, gerânio, cravo e pimenta, frente a 25 espécies Gram-positivas e negativas e observaram que bactérias Gram-positivas eram mais suscetíveis que as Gram-negativas, tendo óleos de orégano e cravo apresentado uma zona de inibição de $18,9 \mathrm{~mm}$ e $14,9 \mathrm{~mm}$, respectivamente, sobre cepas de $S$. aureus e $29,5 \mathrm{~mm}$ e $11,7 \mathrm{~mm}$ sobre as cepas de E. coli. Segundo Burt (2004) a maioria dos estudos que investigam a ação dos óleos essenciais em relação aos micro-organismos patogênicos em alimentos concorda que, geralmente, os óleos são ligeiramente mais ativos para as bactérias Grampositivos do que sob as bactérias Gram-negativas. As espécies Gram-negativas são menos susceptíveis à ação dos óleos essenciais devido à existência de uma membrana exterior que cerca a parede celular, o qual restringe a difusão de compostos hidrofóbicos através de parede externa.

No entanto, a maior susceptibilidade à ação de antimicrobianos naturais de acordo com o Gram não foi constatado por Ushimaru et al. (2007), ao estudarem a ação antimicrobiana dos extratos metanólicos de cravo-da-índia (Caryophyllus aromaticus L.) e alho (Allium sativum L.) sobre bactérias Gram negativas (Escherichia coli e Salmonella) e Gram-positivas (Staphylococcus aureus e Enterococcus sp) e verificaram que o extrato metanólico de cravo-da-índia (95mg/ $\mathrm{mL}$ ) foi mais eficaz para as bacterianas Gram positivas e os extratos metanólicos de alho $(133 \mathrm{mg} / \mathrm{mL})$ apresentaram maior eficácia contra as bactérias Gram-negativas estudadas. Embora os autores ressaltem a importância de se avaliar as concentrações dos extratos secos.
Segundo Martino et al. (2009), o óleo essencial de orégano mostrou ação principalmente contra as bactérias Gram positivas, entre as quais $S$. epidermidis foi a mais inibibida. Entre as bactérias Gram-negativas, apenas E. coli foi inibida pelo óleo. Busatta et al. (2007) estudaram a atividade antimicrobiana do óleo essencial orégano(Origanum vulgare) contra várias bactérias patogênicas, como Staphylococcus aureus, Escherichia coli, Salmonella choleraesius, através do método de difusão em disco, e verificaram que a Salmonella choleraesius apresentou maior halo de inibição $(29,0 \pm 0,08 \mathrm{~mm})$ que as demais cepas testadas.

Santurio et al. (2007), após avaliar a atividade antibacteriana de óleos essenciais extraídos de orégano (Oreganum vulgare), tomilho (Thymus vulgaris) e canela (Cinnamomum zeylanicum), frente a 60 isolados de Salmonella enterica, compreendendo 20 sorovares, todos de origem avícola, através do método de microdiluição em caldo, conclui que o óleo essencial de orégano apresentou maior poder inibitório que os demais óleos. Porém, o autor salienta que as comparações destes resultados com estudos similares devem ser cautelosas, na medida em que a grande maioria dos estudos emprega a técnica de difusão em ágar, fornecendo resultados referentes ao diâmetro de inibição, expressos em milímetros; mesmo os estudos de microdiluição em caldo, na grande maioria dos casos, não seguem procedimentos padronizados, como os empregados no referido trabalho.

No presente estudo se verificou que o óleo essencial da casca do limão (Citrus limonum medica) não apresentou atividade sobre todas as bactérias analisadas (Tabela 1). A utilização de óleo essencial de limão como agente antimicrobiano frente a microrganismos patogênicos em alimentos é pouco explorada, no entanto, é possível encontrar pesquisas em outras áreas e na forma de extratos, como o estudo de Soares et al. (2008) que avaliaram a atividade antibacteriana in vitro de tinturas das folhas do cajá, da casca do limão e das folhas do 
jenipapo sobre micro-organismos da cavidade bucal, Staphylococcus aureus (ATCC 25923), Streptococcus mutans (ATCC 2575), Streptococcus sobrinus (ATCC 27609), e Lactobacillus casei (ATCC 7469) e observaram que a tintura de cajá e do limão foram as que obtiveram os melhores resultados.

Já Johann et al. (2007) avaliaram a atividade antimicrobiana do extrato da casca do limão $(C$. limon), nas concentrações de 7,8 a $1000 \mu \mathrm{g} / \mathrm{ml}$, frente aos micro-organismos $S$. aureus e E. coli e constataram que o extrato apresentou atividade antimicrobiana e a Concentração Inibitória Mínima para $S$. aureus foi de $1000 \mu \mathrm{g} / \mathrm{ml}$ e $500 \mu \mathrm{g} / \mathrm{ml}$ para E. coli.

Enquanto Araújo (2007) avaliou a atividade antimicrobiana dos sumos de cebola (Allium cepa), tomate (Solanum lycopersicum, L.), pimentão (Capsicum cordiforme), pimenta (Capsicum sp.), limão (Citrus limon), maracujá (Passiflora alata), melancia (Citrullus lanatus), laranja doce (Citrus sinensis), laranja azeda (Citrus aurantum Linn.) e uva (Vitis vinifera), frente a isolados clínicos de Staphylococcus aureus, Staphylococcus epidermidis, Staphylococcus saprophyticus, Micrococcus luteus,
Enterococcus faecalis, Escherichia coli e Candida albicans e constatou que os microrganismos Grampositivos apresentaram maior poder de inibição que os demais, sendo que o sumo do limão demonstrou maior atividade em relação aos demais sumos utilizados. Vale ressaltar que o presente estudo avaliou a atividade de óleos essenciais e não do sumo do limão.

$\mathrm{Na}$ Tabela 2 foram apresentados as concentrações inibitórias mínimas (CIM) dos óleos que apresentaram a atividade frente a todas a cepas testadas e baseado nos resultados pode-se observar que todos os microrganismos foram suscetíveis à ação do óleo essencial de orégano, com uma variação nos valores de CIM de 0,25-0,5 mL / $\mathrm{mL}$.

$\mathrm{Du}$ et al. (2009) estudaram a atividade antimicrobiana dos óleos de pimenta da Jamaica, alho e orégano sobre Escherichia coli O157:H7, Salmonella enterica e Listeria monocytogenes e constataram que a atividade antimicrobiana do óleo de orégano foi maior do que a atividade dos outros óleos, quando adicionados em um filme para a conservação de alimentos, variando-se a concentração de $0 \%$ (controle) a $3 \%$ p/p.

Tabela 2. Resultado da Concentração Mínima Inibitória de óleos essenciais de cravo e orégano. $(\mathrm{mL} / \mathrm{mL})$.

\begin{tabular}{|c|c|c|}
\hline \multirow{3}{*}{$\begin{array}{l}\text { Bactéria } \\
\text { Isolados do vôngole } \\
\end{array}$} & \multicolumn{2}{|c|}{ Óleos essenciais } \\
\hline & Cravo & Oregano \\
\hline & \multicolumn{2}{|c|}{ (Diâmetro dos halos em milímetros) } \\
\hline S.aureus isolado 1 & 0.5 & 0.25 \\
\hline S.aureus isolado 2 & 0.5 & 0.25 \\
\hline E. coli isolado 1 & 1.0 & 0.5 \\
\hline E. coli isolado 2 & 1.0 & 0.5 \\
\hline \multicolumn{3}{|l|}{ Cepas padrão ATCC } \\
\hline S. cholerasuis & 1.0 & 0.5 \\
\hline S. aureus & 0.5 & 0.25 \\
\hline E.coli & 1.0 & 0.5 \\
\hline
\end{tabular}


Resultados de CIM do óleo essencial de orégano obtidos neste trabalho são da mesma ordem de grandeza que os encontrados por Bussata et al. (2007), que verificaram que a Escherichia coli, Salmonella ssp. e Staphylococcus aureus apresentaram os respectivos valores 0,$46 ; 0,46 \mathrm{e}$ $0,23 \mathrm{~mL} / \mathrm{mL}$ enquanto o presente estudo, a CIM para o mesmo óleo foram de 0,$5 ; 0,5$ e $0,25 \mathrm{~mL} / \mathrm{mL}$.

Baseado na Tabela 2 observa-se que o óleo de cravo inibiu as cepas estudas com uma variação nos valores de CIM de 0.5-1,0 mL / mL, sendo menos eficaz sobre as cepas de E. coli e Salmonella. Hoffmanno (1999), apos testar óleo de cravo concluiu que este óleo, na concentração de 10,0\%, inibiu completamente o crescimento de todos os vinte e um micro-organismos testados, dentre eles S. aureus, B. cereus e Salmonella enteriditis.

\section{Conclusão}

Os resultados obtidos mostraram que:

O desempenho satisfatório dos óleos estudados foi alcançado com uma concentração relativamente baixa dos óleos essenciais de cravo e orégano sobre todas as bactérias testadas.

O óleo essencial de alho que não apresentou atividade frente às cepas de E. coli.

O óleo essencial de orégano apresentou maior potencial inibidor que o óleo de cravo frente às bactérias de S. aureus, E. coli e Samonella.

O óleo essencial de limão não apresentou atividade antibacteriana.

As cepas de $S$. aureus apresentaram as menores concentrações inibitórias mínimas em relação às cepas de Salmonella e E. coli frente aos óleos de cravo e orégano.

As concentrações inibitórias mínimas variaram entre $0,25 \%$ a $1 \%$ para os óleos de cravo e orégano.

\section{Referencias}

ARAÚJO, C. D. Atividade antibacteriana in vitro e in sito de Allium tuberosum - Rottler ex Spengl (alho "nirá", alho "japonês", "jiucai", alho "chinês") - Liliaceae -sobre agentes de toxinfecções alimentares. 2007. Dissertação (Mestrado em Ciências Veterinárias) - Faculdade de Veterinária. Universidade Federal do Rio Grande do Sul, Porto Alegre.

AYALA-ZAVALA, J. F.; GONZÁLEZ-AGUILAR, G. A.; DEL-TORO-SÁNCHEZ, L. Enhancing safety and aroma appealing of fresh-cut fruits and vegetables using the antimicrobial and aromatic power of essential oils. Journal Food Science, Chicago, v. 74, n. 7, p. 84-91, sept. 2009.

BERNBOM, N.; NG, Y. Y.; PALUDAN-MÜLLER, C.; GRAM, L. Survival and growth of Salmonella and Vibrio in som-fak, a Thai low-salt garlic containing fermented fish product. Int J Food Microbiology, Holanda, v. 134, n. 3, p. 223-229, sept. 2009.

BODINI, S. F.; MANFREDINI, S.; EPP, M.; VALENTINI, S.; SANTORI, F. Quorum sensing inhibition activity of garlic extract and p-coumaric acid. Lett Applied Microbiology, Inglaterra, v. 49, n. 5, p. 551-5, nov. 2009.

BRASIL. Agência Nacional de Vigilância Sanitária (ANVISA). Resolução RDC N² 278/2005. Dispõe sobre o regulamento técnico sobre o manual de procedimentos básicos para registro e dispensa da obrigatoriedade de registro de produtos pertinentes à área de alimentos. Brasília, DF, 22 de setembro de 2005.

BURT, S. Essential oils: their antibacterial properties and potential applications in foods - a review. International Journal of Food Microbiology, Holanda, v. 94, n. 3, p. 223-253, ago. 2004.

BUSATTA, C.; MOSSI, A. J.; RODRIGUES, A. R. M.; CANSIAN, R. L.; OLIVEIRA, J. V. Evaluation of Origanum vulgare essential oil as antimicrobial agent in sausage. Brazilian Journal of Microbiology, São Paulo, v. 38, n. 4, p. 610-616, oct./dec. 2007.

DORMAN, H.; DEANS, S. Antimicrobial agents from plants: antibacterial activity of plant volatile oils. $J$ Applied Microbiology, Reino Unido, v. 88, n. 2, p. 30816, feb. 2000.

DU, W-X; OLSEN, C. W.; AVENA-BUSTILLOS, R. J.; MCHUGH, T. H.; LEVIN, C. E.; FRIEDMAN, M. Antibacterial effects of allspice, garlic, and oregano essential oils in tomato films determined by overlay and vapor-phase methods. Journal Food Science, Chicago, v. 74, n. 7, p. 390-397, sept. 2009.

FARAG, R. S.; DAW, Z. Y.; HEWEDI, F. M.; EL- 
BAROTY, G. S. A. Antimicrobial activity of some egyptian spice essential oils. Journal of Food Protection, Estados Unidos, v. 52, n. 9, p. 665-667, 1989.

HEMAISWARYA, S.; DOBLE, M. Synergistic interaction of eugenol with antibiotics against Gram negative bacteria. Phytomedicine, Alemanha, v. 16, n. 11, p. 997-1005, nov. 2009.

HOFFMANN, F. L.; SOUZA, S. J. F.; GARCIA-CRUZ, C. H.; VINTURIM, T. M.; DUTRA, A. L. Determinação da atividade antimicrobiana "in vitro" de quatro óleos essenciais de condimentos e especiarias. Boletim do CEPPA, Curitiba, v. 17, n. 1, p. 11-20, 1999.

INDU, M. N.; HATHA, A. A. M.; ABIROSH, C.; HARSHA, U.; VIVEKANANDAN, G. Antimicrobial activity of some of the South-Indian spices against serotypes of Escherichia coli, Salmonella, Listeria monocytogenes and Aeromonas hydrophila. Brazilian Journal of Microbiology, São Paulo, v. 37, n. 2, p. 153158, apr.jun. 2006.

JOHANN, S.; OLIVEIRA, V. L.; PIZZOLATTI, M. G.; SCHRIPSEMA, J.; BRAZ-FILHO, R.; BRANCO, A.; SMÂNIA JUNIOR, A. Antimicrobial activity of wax and hexane extracts from Citrus spp. peels. Mem Inst Oswaldo Cruz, Rio de Janeiro, v. 102, n. 6, p. 681-5, sept. 2007.

KHAN, M. S.; ZAHIN, M.; HASAN, S.; HUSAIN, F. M.; AHMAD, I. Inhibition of quorum sensing regulated bacterial functions by plant essential oils with special reference to clove oil. Lett Appl Microbiology, Inglaterra, v. 49, n. 3, p. 354-60, sept. 2009.

KRUGER, M. F. Controle de Listeria monocytogenes em lingüiça frescal refrigerada através do uso de óleo essencial de orégano e nisina. 2006. Dissertação (Mestrado em Ciência dos Alimentos) - Faculdade de Ciências Farmacêuticas. Universidade Estadual de São Paulo, São Paulo.

LAMBERT, R. J. W.; SKANDAMIS, P. N.; COOTE, P. J.; NYCHAS, G. A study of the minimum inhibitory concentration and mode of oregano essential oil, thymol and carvacol. Journal of Apllied Microbiology, Reino Unido, v. 91, n. 3, p.453-462, 2001.

LASZLO AROMATERAPIA. Disponível em: < http:// www.laszlo.ind.br/>. Acesso em: 05 jun. 2010.

MARTINO, L. D.; VINCENZO, D. F.; FORMISANO, C.; MIGNOLA, E.; SENATORE, F. Chemical composition and antimicrobial activity of the essential oils from three chemotypes of Origanum vulgare L. ssp. hirtum (Link) Ietswaart growing wild in Campania (Southern Italy). Molecules, Suíça, v. 14, n. 8, p. 2735-46, 2009.

MENDONÇA, A. T. Efeito dos óleos essenciais de condimentos sobre o crescimento de $S$. aureus em ricota cremosa. 2004. Tese (Pós-graduação em Ciência dos Alimentos) - Universidade Federal de Lavras. Lavras, Minas Gerais.

MISHARINA, T. A.; SAMUSENKO, A. L. Antioxidant properties of essential oils from lemon, grapefruit, coriander, clove, and their mixtures. Applied Biochemistry and Microbiology, Rússia, v. 45, n. 4, p. 438-442, 2008.

NASCIMENTO, P. F. C.; NASCIMENTO, A. C.; RODRIGUES, C. S.; ANTONIOLLI, A. R.; SANTOS, P. A. O.; BARBOSA JÚNIOR, A. M.; TRINDADE, R. C. Atividade antimicrobiana dos óleos essenciais: uma abordagem multifatorial dos métodos. Revista Brasileira de Farmacognosia, João Pessoa, v. 17, n. 1, p. 108-113, 2007.

NATIONAL COMMITTEE FOR CLINICAL LABORATORY STANDARDS - NCCLS. Performance standards for antimicrobial disk susceptibility tests. Approved standards M7-A5. Wayne, PA, 2000.

PEREIRA, A. A.; CARDOSO, M. G.; ABREU, L. R.; MORAIS, A. R.; GUIMARÃES, L. G., SALGADO, A. P. S. P. Caracterização química e efeito inibitório de óleos essenciais sobre o crescimento de Staphylococcus aureus e Escherichia coli. Ciência e Agrotecnologia, Lavras, v. 32, n. 3, p. 887-893, maio/jun. 2008.

SCHUCK, V. J.A.; MARISAFRATINI, M.; CRISTIANE, S.; RAUBER, C. S.; HENRIQUES, A.; SCHAPOVAL, E. E. S. Avaliação da atividade antimicrobiana de Cymbopogon citratus. Revista Brasileira de Ciências Farmacêuticas, São Paulo, v. 37, n. 1, jan./abr. 2001.

SOARES, D. G. S.; OLIVEIRA, C. B.; DRUMOND, M. R. S.; TRAVASSOS, D. B.; SILVA, C. A.; PADILHA, W. W. N. Atividade antibacteriana de tinturas de plantas tropicais sobre microorganismos da cavidade bucal. Revista Odontológica de Araçatuba, Araçatuba, v. 29, n. 1, p. 20-24, jan./jun. 2008.

SOUZA, E. L. Potencial antimicrobiano do óleo essencial de orégano (Origanum vulgare L.): uma abordagem para uso em sistemas de conservação de alimentos. 2006. Tese (Doutorado em Nutrição) - Universidade Federal de Pernambuco, Recife.

USHIMARU, P. K.; SILVA, M. T. N.; DI, S. C.; BARBOSA, L.; FERNANDES JUNIOR, A. Antibacterial activity of medicinal plant extracts. Brazilian Journal of Microbiology, São Paulo, v. 38, n. 4, p. 717-719, oct./dec. 2007.

ZAIKA, L. Spices and herbs - their antimicrobial activity and its determination. Journal of Food Safety, Estados Unidos, v. 9, n. 2, p. 97-118, 1988. 